\title{
Business users and the information system development process: a need to know basis
}

\author{
D. R.Lawrence
}

University of Wolverhampton, Wulfruna St., Wolverhampton, WV1 1SB, UK. email: cm1994@ccub.ac.wlv.uk http://www.wlv.ac.uk/ ${ }^{\sim} c m 1994$

\section{H. U. Shah}

Staffordshire University

P.O. Box 334, Beaconside, Stafford ST18 ODG, UK

e-mail: H.Shah@soc.staffs.ac.uk

\section{P. A. Golder \\ Aston University,}

Birmingham, B4 7ET, UK.

email: golderpa@aston.ac.uk

\footnotetext{
Abstract

We discuss the growth, the benefits and risks, of business users taking a more active part in developing computerised information applications. After briefly discussing IS (information system) development management issues relating to user based IS development, we propose a framework for indicating the extent to which particular business users need to know about the process of developing IT systems. We then outline our recent research which addresses the measurement of BUD (Business User Development) success factors and identifies typical IT involvement levels of business users.

We can conclude that BUD outcome effectiveness can be predicted using measures of contributing factors, a framework can be used to indicate the level of IT development process knowledge needed by business users, and that improved tool support would enable business users to be much more actively and directly involved in IS development. Given the current tool support environment, many agree that business users and managers need to be educated to acquire 'good' systems design and implementation techniques. An important assertion in this paper is that appropriately 
designed tool support would significantly reduce the need for IT training of business users.

\section{Keywords}

Business users, end users, application development, effectiveness, modelling

\section{INTRODUCTION}

We are currently faced with a business community who are largely not satisfied with the suitability of implemented software systems, and whose businesses are not benefiting sufficiently from the potential of IT (Warden, 1989; Rauterburg, 1992). This is often referred to as the 'software crisis' (Swatman, 1992).

The introduction of networked personal workstations in recent years, together with the proliferation of PC-based software, has precipitated the trend of transferring powers of choice and operation of software away from centralised IT departments to the business personnel intending to utilise or benefit from the implementations (Amoroso, 1992; Davies, 1990; Huff, 1992).

The aim of our research is to gain a better understanding of how the potential of business users (to develop systems) can be measured, and improved.

\section{ANALYST-USER COMMUNICATION}

A survey study (Stobart, 1991) has identified that poor user-analyst communication is a key software development problem area, and this is supported by others (Joshi, 1992). It is widely recognised that the more successful analyst/designers are those that, in addition to substantial IT skills, have knowledge of the application area and so can map between the expected business behaviour and the structure of the software needed to support this behaviour (Warden, 1989; Curtis, 1992).

Research suggests that the issues associated with the roles and interaction of analysts and users are complex and that there are inherent conflicts (Shah, 1994; Ward, 1994). Research (Miller, 1993) has shown that the effectiveness of the requirements analysis process can be enhanced by focusing on the user's view of their needs rather then the systems analyst's interpretation of them.

One approach to addressing the problematic issue of analyst-user communication is to consider user-led project work. The premise is that user-led development reduces the need for the communication of requirements and IS models between different role players.

\section{END USER COMPUTING}

End User Computing (EUC) can be defined as the direct use of computing resources by office, professional or managerial personnel (Bergeron, 1993). We also utilise the term Business User Development (BUD), which refers to the activity of building computerised information systems of varying size, by people who primarily have a business role associated with the information system concerned. 
The 'meta-analysis' of previous studies shows that the relationship between user involvement and system success is positive and significant (Pettingell, 1988). This is supported in findings from an Australian field study (Nicholis, 1990), and other work concludes that the effectiveness of technology increases when more directly in the hands of business developers (Boone, 1991; Dodd, 1994; Khan, 1992).

It has been suggested (Amoroso, 1992) that BUD eliminates the problems associated with ineffective communications between analysts and end users, and produces the added advantage of ownership transfer to the end users.

\section{ASSOCIATED RISKS OF USER DEVELOPMENT}

There is a widely expressed concern about the potential risks associated with BUD, resulting from the elimination of the IT specialist role (Cale, 1994). A study (Sumner, 1987) shows that end users directly involved in development projects tend not to utilise some of the practices traditionally followed (eg. data validation, documentation and security). The use of Information Centres may be a useful way of providing technical support to users in these areas (Guimaraes, 1994). It has been suggested (Salchenberger, 1993) that BUD tends to suffer from the lack of sufficient requirements analysis, and proposed that a comprehensive set of guidelines might help end users apply a structured approach. We sympathise with these findings, but suggest that more powerful tool support could considerably reduce these problems.

\section{USER BASED IS DEVELOPMENT - MANAGEMENT RESPONSIBILITIES}

There is a growing responsibility of management, in many cases with no computingrelated qualifications, to exercise control over substantial IT resources (Harris, 1992). We support the notion that the monitoring and control of BUD activities should be managed by business managers carrying out the role of IS management (Khan, 1992). Modern organisations utilise a variety of approaches, within a range of environments, to develop and manage the development of their information systems. Hence the extent to which business personnel require to know about the process of developing IT solutions for a business information system need will vary. Table $1 \mathrm{a}$ and Table $1 \mathrm{~b}$ illustrate a suggested framework for indicating such requirements. 
Table 1a: Process Knowledge Framework (part (a))

$R E Q^{\prime} T$

LEVELS

Higher

Lower
IT development process knowledge (business users)

influences

TASK COMPLEXITY

DEVELOPMENT STYLE

User Based Development

User Led Projects

User/IT Expert prototyping

IT expert/User prototyping

IT Specialist led project
Multi Dept/Complex systems

Database Design + Processing

Multiple file/screens

Simple Database Queries

Spreadsheets (build)

Spreadsheets (use)

Decision Support applications (use)

Data entry applications (use)

View information

Table 1b: Process Knowledge Framework (part (b))

Technical Support Tool Support

(assuming user-based development style and a given task complexity)

Higher

Centralised IT dept.
(no user support)

Traditional environment

Window based environment

IT dept user support

Info Centre support

4 GL/application builders

Decision Support Tools

Decentralised Specialists

User Targeted Builder Tools

Lower

User Based Support Groups

User Support Infrastructure

It follows that as the required levels of 'IT development process knowledge' rise then the training/education needs of business users will increasingly need to be considered to make up for any shortfall in skills and experience. We contend that it could be too much to expect that typical business users should be highly skilled in systems development techniques and also build up and maintain extensive business related knowledge. Apart from the practical problem of providing effective education, there is the potential problem that attention will be diverted from their primary role (in terms of practicing and maintaining business expertise). The framework (Tables la and 1b) indicates that for a given task complexity, and assuming that the project is 'user based', the required level of IT development process knowledge can be reduced by providing improved support for business users.

Our research involves the consideration of advanced tool support for BUD participants. The objective is to develop tool support which assists with IT design 
decisions (Shah, 1996) - building the relevant IT 'expertise' into the tool itself, which is an idea supported elsewhere (Benham, 1993).

As a precursor to tool prototyping we have completed a survey to gain a better understanding of the factors which influence the effectiveness of BUD outcomes, to form a view of the levels of EUC and BUD activities currently practised in typical business organisations, and to assess the potential for business user empowerment.

\section{USER SURVEY}

The survey used a questionnaire instrument previously piloted (Lawrence, 1995). The results and conclusions are based on 69 responses received from a total of 24 UK organisations, out of 80 organisations approached, covering sectors such as financial services, building, public services, retailing, and engineering. In all cases, the contacts were asked to arrange for questionnaires to be completed by personnel who primarily had a business role within the organisation, and also had some interaction with IT. The participants ranged from office clerks, through experienced professionals, to a divisional manager.

We used the questionnaire survey to gain ordinal measures of BUD contributing factors for particular individuals, and also of BUD outcome effectiveness. There have been many attempts to model and measure the criteria for success of an end user developed application (Rivard, 1994), but no universal set of factors has been established. We chose factors on the strength of practical personal experience in the IS development area. The selected factors (IT experience, business/IS knowledge, role power/freedom, and tool suitability) are also in harmony with conclusions made in reviews of previous research in this area (Brancheau, 1993). In our studies (we follow (Bergeron, 1993) and (Brancheau, 1993)) we view BUD effectiveness in terms of the levels of 'user access to information', 'actual usage', 'user satisfaction', 'business benefit', and 'implementation frequency'.

Total scores are calculated for each contributing factor and compared to scores for perceived BUD effectiveness. There are also text based questions, which are designed mainly for cross-reference purposes, and a section which deals with ascertaining the level of involvement in specific EUC and BUD activities.

\section{BUD EFFECTIVENESS PREDICTION}

This area of our survey analysis is discussed in detail elsewhere (Lawrence, 1996), and concludes that each of the contributing factors directly and indirectly influence BUD effectiveness. The role (power and authority) and tools (suitability) factors are shown to be dominant. We can use statistical, as well as less formal, methods to predict outcome effectiveness based on measures of contributing factors - which is very useful in resource/strategic planning.

\section{PROFILE OF EUC ACTIVITIES}


Our questionnaire includes a section which inquires about the involvement of the participant in a fixed set of 28 recognised EUC activities (we have enhanced and extended a list of activities/attributes previously utilised (McLean, 1992)). Tables 2a-2d provide summaries of the results obtained. Each participant in the survey was asked to rate each aspect from 0 to 5 ( 5 being high). Tables $2 \mathrm{a}, 2 \mathrm{~b}, 2 \mathrm{c}$ and $2 \mathrm{~d}$ show the 'top 10' placings of activities in terms of numbers of business users involved, average individual involvement, average outcome satisfaction level, and average tool satisfaction level respectively.

It can be seen that the predominant business user activities still (i.e. even after increases in widespread exposure to IT and end user tools over recent years) seem to relate to wordprocessing and spreadsheet work and the use of databases and database queries. A noticeable feature is that there is a high level of use of e-mail systems. We can also see that there is some evidence of business users being involved in system building activities (albeit in relatively small numbers).

Activities which have high 'avge involvement' also tend to have associated relatively high average values for 'outcome satisfaction' and 'software/tool rating' (see Tables $2 \mathrm{~b}, 2 \mathrm{c}$ and $2 \mathrm{~d}$ ). It is unclear whether increased involvement produces higher levels of satisfaction/tool ratings, or perhaps whether it is the suitability of tools which encourage more involvement, which in turn leads to greater outcome satisfaction. A further point is that building activities tend to be associated with lower tool support ratings.

Table 2a:

Highest number of users

$\begin{array}{lc}\text { Spreadsheets (use) } & 44 \\ \text { Wordprocessing } & 43 \\ \text { Database queries(use) } & 35 \\ \text { Spreadsheets (build) } & 34 \\ \text { Electronic mail (use) } & 34 \\ \text { Small databases (use) } & 23 \\ \text { Company d'bases (use) } & 23 \\ \text { D'base queries(build) } & 22 \\ \text { Desktop publishing } & 20 \\ \text { Syst analysis/design } & 18\end{array}$

Table 2c:

Highest avge outcome satisfaction

$\begin{array}{ll}\text { Spreadsheets (use) } & 3.3 \\ \text { Company d'bases (use) } & 3.3 \\ \text { Electronic mail (use) } & 3.1 \\ \text { Manufacturing sys (use) } & 3.1 \\ \text { Wordprocessing } & 3.0 \\ \text { Database queries (use) } & 2.9 \\ \text { Company databases(build) } & 2.9 \\ \text { Spreadsheets (build) } & 2.8 \\ \text { Small databases (use) } & 2.8 \\ \text { D'base queries (build) } & 2.8 \\ \text { Prototyping(as developer) } & 2.8\end{array}$

Table 2b: Highest avge involvement

$\begin{array}{lc}\text { Electronic mail (use) } & 4.1 \\ \text { Wordprocessing } & 3.8 \\ \text { Database queries (use) } & 3.7 \\ \text { Spreadsheets (use) } & 3.5 \\ \text { Company d'bases (use) } & 3.5 \\ \text { D'base queries (build) } & 3.5 \\ \text { Spreadsheets (build) } & 3.4 \\ \text { Small databases (use) } & 3.3 \\ \text { Small databases(build) } & 3.3 \\ \text { Transaction systems(use) } & 3.1 \\ \text { Desktop publishing } & 3.1\end{array}$

Table 2d:

Highest avge software/tool rating

$\begin{array}{ll}\text { Spreadsheets (use) } & 3.2 \\ \text { Company d'bases (use) } & 2.9 \\ \text { Electronic mail (use) } & 2.9 \\ \text { Wordprocessing } & 2.8 \\ \text { Spreadsheets (build) } & 2.8 \\ \text { Database queries(use) } & 2.6 \\ \text { Prototyping (as user) } & 2.5 \\ \text { Desktop Publishing } & 2.3 \\ \text { D'base queries (build) } & 2.2 \\ \text { Small databases (use) } & 2.1 \\ \text { Computer Aided Training } & 2.1\end{array}$




\section{SUCCESS FACTOR LEVELS}

Table 3 shows that most of the participants in the survey have levels of IT expertise of either 'medium' or 'high' - which is to be expected as computerisation is no longer a new phenomenon in business. However, we would have expected the proportion to be higher. The number of participants (20 out of 69 ) who seem to have low levels of Business/IS knowledge could be of concern to business managers - who possibly might have expected greater levels of understanding.

Table 3: Success factor levels

\begin{tabular}{|c|c|c|c|}
\hline & \multicolumn{3}{|c|}{ No. of participants at level } \\
\hline FACTOR & LOW & MEDIUM & $H I G H$ \\
\hline IT expertise & 5 & 27 & 17 \\
\hline Business/IS Knowledge & 20 & 13 & 36 \\
\hline Role power/freedom & 40 & 15 & 14 \\
\hline Tool Suitability & 47 & 13 & 9 \\
\hline
\end{tabular}

Table 3 shows that many users have tools which have limited scope and power, and also indicates that a significant proportion of users might also be constrained in BUD activities by the nature of their role/authority. These conclusions are supported by some of the text based responses received.

\section{CONCLUSIONS}

i) We have illustrated the importance of EUC and BUD, and discussed issues related to the management of user involvement in IS development projects. We also propose a framework that helps indicate the extent to which business users need to know about the process of developing an IT solution for a business information system.

ii) We contend that attention should be given to improving tool support for business users actively involved in user-based development projects.

iii) We can predict BUD outcome effectiveness using surveyed measures of the identified contributing factors.

iv). We have shown that the questionnaire enables a detailed profile of the participant and their EUC activities to be constructed. The results suggest that business users in the UK, tend to be involved in EUC activities at the level of wordprocessing, spreadsheeting, database access, and e-mailing. It is a minority which is actively involved at the level of application or system building.

v). Our results show that business users may need improved tool support and role power/freedom to enable them to be more effective in BUD activities. Our future research will include the prototyping of advanced BUD tool support. 


\section{REFERENCES}

Amoroso D.L. \& Cheney P.H. (1992), "Quality End-user Developed Applications: Some Essential Ingredients", Data Base, 23, Winter 1992, p.1-11.

Benham, H.; Delaney, M.; Luzi, A. (1993), "Structured techniques for successful end user spreadsheets", Journal of End User Computing, 5(2), Spring 1993, p. 18-25.

Bergeron F., Rivard S. \& Raymond L. (1993), "Assessment of End-User Computing from an Organisational Perspective", Information Resources Management Journal, Winter 1993, pp.14-25.

Boone G., (1991): "CASE and its challenge for change", International Journal of Software Engineering and Knowledge Engineering, Vol 1 No. 2, 1992, pp. 151163.

Brancheau J.C. \& Brown C.V. (1993), "The Management of End User Computing: Status and Directions", ACM Computing Surveys, 25(4), December 1993.

Cale, E.G., Jr (1994), "Quality issues for end-user developed software", Journal of Systems Management, 45(1), Jan 1994, p. 36-9.

Curtis B. (1992), "The case for process", IFIP working conference on The Impact of Computer Supported Technologies on Information Systems Development, Minneapolis Minnesota, June 1992, North-Holland.

Davies D. \& Davies D. (1990): "The Effect of Training Techniques and Personal Characteristics on Training End Users of Information System", JMIS(7:2), Fall 1990, pp. 93-110.

Dodd, J.L. \& Carr, H.H. (1994), "Systems development led by end-users: an assessment of end-user involvement in information systems development", Journal of Systems Management, 45(8), Aug 1994, p. 34-40.

Guimaraes T. \& Igbaria M. (1994), " Exploring the relationship betwen IC success and company performance", Information and Management, 26(3), pp.133- 141, March 1994.

Harris R.W (1992): "Management control of end-user computing a description of research in progress", Proceedings of the 1992 ACM SIGCPR Conference, 5-7 April 1992, Cincinnatti,USA,ACM New York, 1992, p.33-40.

Huff S.L., Munro M.C. \& Marcolin B. (1992), "Modelling and Measuring End User Sophistication", Proceedings of ACM SIGCPR conference, April 1992, Cincinnati, Ohio, ACM Press, 1992.

Joshi K. (1992), "Interpersonal Skills for Cooperative User-Analyst Relationships: Some Research Issues", Data Base, 23 (1), Winter 1992, pp23-25.

Kappelman L.A. \& McLean E.R. (1994), "User Engagement in the Development, Implementation, and Use of Information Technologies", Proceedings of 27th Hawaii International Conference on System Sciences, p.512-521, Vol. 3, Jan 1994.

Khan E.H. (1992), "The Effects of Information Centres on the Growth of End User Computing", Information and Management, 23 (5), pp.279-289.

Lawrence D.R., Shah H.U. \& Golder P.A. (1995), "A study to validate an end user computing model - Towards Predictive Quality", Proceedings of Software Quality Management III (Vol 1), 3-5th April 1995, Seville, Spain.

Lawrence D.R., Shah H.U. \& Golder P.A. (1996), "Business User Development Success Factor Measurement", Proceedings of PRIISM '96 Conference, Maui, Jan 1996). 
McLean E. R. \& Kappelman L.A. (1992), "The Convergence of Organisational and End-User Computing", Journal of Management Information Systems, Winter 19923, (9) No. 3, pp.145-155, 1993.

Miller R.L. , Morley J. \& Raikos P.J. (1993): "Enterprise modeling: user- driven requirements analysis", Proceedings of the IEEE 1993 National Aerospace and Electronics Conference (NAECON 1993), Dayton (OH), USA, 24-28 May 1993, IEEE, New York, 1993, pp. 1010-1016 vol2.

Nicholas P. \& O'Connor M. (1990), Proceedings of the Twenty-Third Hawaii International Conference on System Sciences, Jan 1990, Hawaii USA, IEEE, 1990 pp. 479-486.

Pettingell K., Marshall T. \& Remington W. (1988), "A Review of the influence of User Involvement on System Success", Proceedings of 9th Conference on Information Systems, 1988.

Rauterberg M. \& Strohm O. (1992), "Work organisation and software development", Proceedings of Experiences with the Management of Software Projects 1992, Austria, May 1992, Pergamon 1992.

Rivard, S., Poirier, G., Raymond, L. \& Bergeron, F. (1994): "Development of a measure to assess the quality of user-developed applications", Proceedings of the Twenty-Seventh Hawaii International Conference on System Sciences. Vol.IV: Information Systems: Collaboration Technology Organizational Systems and Technology, Wailea (HI) USA, 4-7 Jan 1994, IEEE, USA, p. 522-31

Salchenberger, L. (1993), "Structured development techniques for user- developed systems", Information and Management24(1), 41-50.

Shah, H.U.; Dingley, S.; Golder, P.A. (1994), "Bridging the culture gap between users and developers", Journal of Systems Management, 45(7), July 1994, p. 1821.

Shah H.U. \& Lawrence D.R. (1996), "A Study of End User Computing and the Provision of Tool Support to Advance End User Empowerment", Journal of End User Computing, Winter 1996.

Stobart S.C., Thompson J.B. \& Smith P. (1991), "Use, problems, benefits and future direction of computer aided software engineering", Information and Software Technology, 33 (9), UK, 1991.

Sumner M. \& Klepper R. (1987), "Information Systems Strategy and End-user Application Development", Data Base, 18, Summer 1987, p. 19-30.

Swatman P. A. \& Swatman P. M. (1992), "Is the Information Systems community wrong to ignore formal specification methods", Proceedings of Managing Information Technology's Organisational Impact II (IFIP), R. Clarke and J Cameron (eds), 1992, Elsevier Science Publishers B.V. (North Holland).

Ward J. \& Peppard (1994), "Reconciling the IT/Business relationship: A Troubled Marriage in Nedd of Guidance", Management challenges in information systems conference proceedings, Cranfield, UK, July 1994.

Worden R. (1989), "Processes of knowledge and software", Proceedings of Expert Systems '88: 8th Annual Technical Conference, Cambridge, Dec 1988. 


\section{BIOGRAPHIES}

D R Lawrence is a senior lecturer at the University of Wolverhampton, UK. His PhD research interests are in the areas of business user computing, the understanding of factors which contribute to the effectiveness of user-led information system development projects, and the improvement of tool support for user-developers. Published work includes papers in Journal of End User Computing, and presented at PRIISM '96, SQM '95, and CAiSE '95 W4.

Dr Hanifa Shah is Reader in Information Systems in the School of Computing at Staffordshire University, UK. Her research concerns the provision of improved tools and techniques to support the development of information systems and databases. She has supervised several doctoral students in this area. Her research has been published in a number of journals including, European Journal of Information Systems, Journal of Information Technology, Journal of End User Computing and Information Technology and People.

P A Golder, Department Of Computer Science and Applied Mathematics, Aston University, UK. Originally qualified and experienced as a statistician, Paul is now mainly involved in Information Systems, Decision Support Systems, Data Modelling and their intersection, both in teaching and research. Recent publications have appeared in DSS, CSCW and IST. 